\title{
Study of Strength Degradation Mechanism of Woven GFRP in Water Environment*
}

\author{
Masahiro KOTANI**, Yusuke YASUFUKU***, \\ Yusuke TAMAISHI*** and Hiroyuki KAWADA** \\ **Department of Applied Mechanics and Aerospace Engineering, Waseda University, \\ 3-4-1 Okubo, Shinjuku-ku, Tokyo, Japan \\ E-mail: robot_5ta2@toki.waseda.jp \\ ***Department of Applied Mechanics and Aerospace Engineering, Graduate School of Waseda \\ University, \\ 3-4-1 Okubo, Shinjuku-ku, Tokyo, Japan
}

\begin{abstract}
This paper presents an experimental investigation into the effects of water temperature and immersion times on the tensile strength degradation of plain-woven glass fiber reinforced plastics (GFRP) laminates. GFRP specimens were tested as-received and after hydrothermal aging in deionized water at $40{ }^{\circ} \mathrm{C}$, $80{ }^{\circ} \mathrm{C}, 95^{\circ} \mathrm{C}$ to evaluate their tensile properties. The strength and rupture strain had a tendency to decrease drastically in the early stages and to saturate toward certain strength with long-term aging, regardless of the water temperature. The fracture surfaces were examined by scanning electron microscopy (SEM) to study the fracture mechanisms of woven GFRP after hydrothermal aging. While the strength of the glass fiber decreased, the fracture surfaces of the E-glass fibers flattened, and the mirror zones on the fracture surfaces enlarged. Interfacial degradation was confirmed by fiber pull-out, and the debonded fibers showed no resin matrix adhesion to the fiber surfaces. These experimental results suggest that the degradation in the strength of woven GFRP is dominated by degradation of their fiber reinforcement and the fiber/matrix interface.
\end{abstract}

Key words: GFRP, Strength Degradation, Water Environment, Hydrothermal Aging

\section{Introduction}

Glass fiber reinforced plastics (GFRP) have high specific strength, specific stiffness, and corrosion resistance as compared to previously used structural materials. The use of GFRP structures is widespread and still increasing in applications such as daily supplies, chemical storage tanks, wind turbine blades, and marine structures. The long-term reliability of GFRP structures in hostile environments is ensured by using design concepts that leave a good safety margin in order to avoid corrosion by environmental agents. However, some unfortunate accidents involving the use of GFRP structures under hostile environments have already been reported ${ }^{(1)}$. The cause of such accident is concluded to be stress corrosion cracking (SCC) in the GFRP; this is induced by the interaction between environmental agents and the applied stress.

Most of the researches dealing with SCC in GFRP have focused on its macroscopic degradation properties such as crack propagation within woven GFRP laminates in 
corrosive environments ${ }^{(2),(3)}$. Kawada and Srivastava established in previous work that solution effects on SCC are dominant to its diffusivity; therefore hot-water environments are valid for investigating the SCC of GFRP ${ }^{(4)}$. Exposure to high temperature also has a destructive effect on the GFRP performance, for example, by inducing hydrothermal aging ${ }^{(5),(6)}$. It has also been reported that exposure of GFRP to corrosive environments results in irreversible changes to their constituents: fiber reinforcement, resin matrix, and fiber/matrix interface ${ }^{(7)-(9)}$. Liao et al. investigated the strength degradation of unidirectional GFRP qualitatively by studying the tensile and the flexural strengths in various environments ${ }^{(10)}$. They showed that both the tensile and the flexural strengths of unidirectional GFRP decrease with environmental aging. However, commercially available woven GFRP structures have various failure modes as compared to unidirectional GFRP; these failure modes are related to their stacking sequence and loading direction. It would, therefore, be useful to clarify the fracture mechanisms of woven GFRP after environmental aging to improve the long-term reliability of commercially used GFRP structures in hostile corrosive environments.

In the present study, woven GFRP were immersed in deionized water at various temperatures to investigate the strength degradation mechanism. Then, the tensile properties of woven GFRP were evaluated as-received and after hydrothermal aging (by immersion in water). In this paper, specimens tested as-received (without immersion in water) are denoted as "dry" specimens, and specimens tested after hydrothermal aging are denoted as "wet" specimens. The effects of environmental aging on GFRP strength were studied using woven GFRP specimens by measuring their tensile properties and from scanning electron microscopy (SEM) observations of their fracture surfaces.

\section{Experimental}

\subsection{Specimens}

The specimens used in this study were plain-woven GFRP laminates consisting of plain-woven E-glass cloth and the vinylester resin matrix. The woven GFRP laminates were fabricated using a hot-press method, and the curing conditions were determined by the differential scanning calorimetry (DSC) analysis. The fiber volume fraction of the laminates was kept at approximately $36.1 \%{ }^{(11)}$. Tensile test specimens were cut from a woven GFRP laminates panel after being released from the mold, and the edges of each specimen were polished, using emery paper, in order to avoid edge effects. The specimen geometry for the tensile test is shown in Fig. 1; this was determined by finite element method (FEM) analysis so as to avoid fracture around the pin-hole resulting from stress concentration. The mechanical properties of the constituents are listed in Table 1.

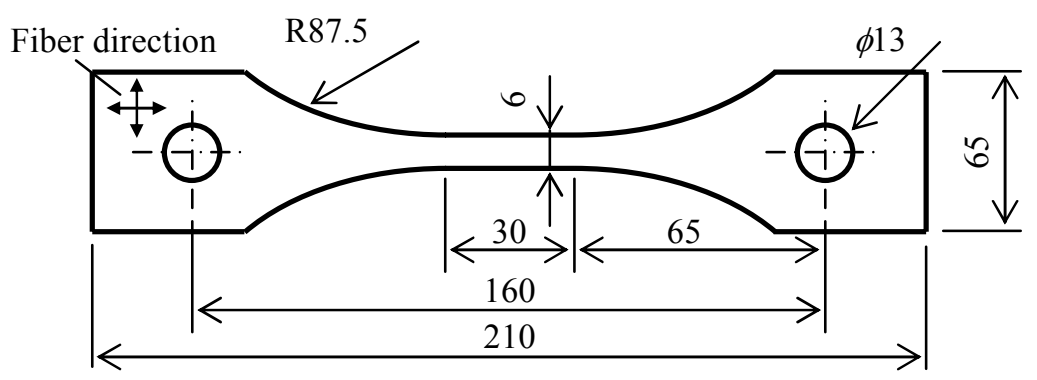

Fig. 1. Specimen geometry of woven GFRP for tensile test.

\subsection{Dynamic mechanical analysis}

The dynamic mechanical analysis (DMA) of neat vinylester resin was conducted to evaluate its glass transition temperature $T_{\mathrm{g}}$ and mechanical properties after hydrothermal 
Table 1. Material properties of the constituents.

\begin{tabular}{ccc}
\hline \hline & Resin matrix & Fiber reinforcement \\
\hline Material & Vinylester & E-glass \\
\hline Strength $\sigma(\mathrm{MPa})$ & 75 & 3430 \\
\hline Stiffness $E(\mathrm{GPa})$ & 3.00 & 72.5 \\
\hline Density $\rho\left(\mathrm{g} / \mathrm{cm}^{3}\right)$ & 1.10 & 2.54 \\
\hline $\begin{array}{c}\text { Coefficient of thermal } \\
\text { expansion } \alpha\left(\mathrm{K}^{-1}\right)\end{array}$ & $6.1 \times 10^{-5}$ & $5.5 \times 10^{-6}$ \\
\hline
\end{tabular}

aging. The specimen used for the DMA was a bar-shaped specimen of dimensions $60 \mathrm{~mm} \times$ $10 \mathrm{~mm} \times t 2 \mathrm{~mm}$ prepared from neat vinylester resin. The storage modulus $E^{\prime}$, loss modulus $E$ ", and glass transition temperature $T_{\mathrm{g}}$ were measured after immersion in water at $40{ }^{\circ} \mathrm{C}$, $80^{\circ} \mathrm{C}$, and $95^{\circ} \mathrm{C}$.

\subsection{Water absorption tests}

Water absorption tests of woven GFRP were conducted in order to investigate their internal water diffusion properties. The weight and the elongation of a bar-shaped specimen $(140 \mathrm{~mm} \times 20 \mathrm{~mm} \times t 2 \mathrm{~mm})$ were measured to evaluate the weight gain $\Delta M$ and the swelling strain $\varepsilon_{\text {swell }}$ after immersion in water at $40{ }^{\circ} \mathrm{C}, 80^{\circ} \mathrm{C}$, and $95^{\circ} \mathrm{C}$, respectively ${ }^{(12)}$. The weight gain $\Delta M$ and the swelling strain $\varepsilon_{\text {swell }}$ are expressed by the following equations:

$$
\begin{aligned}
\Delta M & =\frac{M(t)-M(0)}{M(0)} \\
\varepsilon_{\text {swell }} & =\frac{L(t)-L(0)}{L(0)}
\end{aligned}
$$

where $M(t)$ is the uptake of weight at time $t, M(0)$ is the initial weight, $L(t)$ is the length at time $t$, and $L(0)$ is the initial length, respectively.

\subsection{Tensile tests}

Tensile tests of woven GFRP were conducted in air, after hydrothermal aging (immersion in deionized water), at the same temperature as that of the water used in the hydrothermal aging. Loading was introduced by means of a $250-\mathrm{kN}$ capacity testing machine; the testing speed was $1.0 \mathrm{~mm} / \mathrm{min}$. A strain gage was bonded in the gage section to measure the axial strain on the specimen during the tensile tests. Experimental conditions for hydrothermal aging are listed in Table 2 .

Table 2. Experimental conditions for hydrothermal aging.

\begin{tabular}{c|c}
\hline \hline Solution & Deionized water \\
\hline Temperature $T\left({ }^{\circ} \mathrm{C}\right)$ & $40,80,95$ \\
\hline Immersion time $t$ (hour) & 0 (dry), 250, 500, 1000, 2000,3000, 4000 \\
\hline
\end{tabular}

\section{Results and Discussions}

\subsection{Hydrothermal aging of vinylester resin}

The storage modulus $E^{\prime}$ and the glass transition temperature $T_{\mathrm{g}}$ of neat vinylester resin after immersion in water at $95{ }^{\circ} \mathrm{C}$ are shown in Fig. 2. The plasticization of the vinylester resin, i.e. the decrease in the storage modulus $E^{\prime}$ was ascertained from the DMA tests, especially at $95{ }^{\circ} \mathrm{C}$. A slight increase in $\tan \delta$ was observed at around $100^{\circ} \mathrm{C}$, possibly due to 
(a) Storage modulus

Dry (As-recierved) - Wet $\left(95^{\circ} \mathrm{C} 500\right.$ hours $)$

(b) $\tan \delta$

Dry (As-recierved)
Wet $\left(95^{\circ} \mathrm{C} 500\right.$ hours $)$
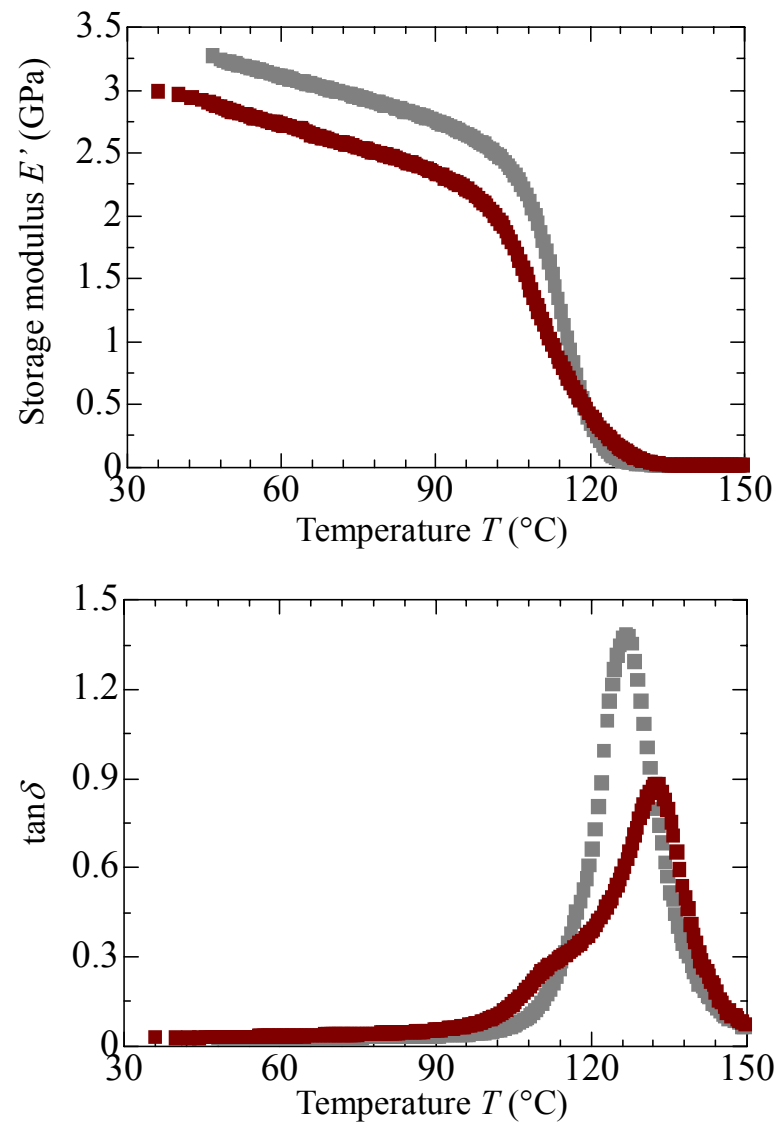

Fig. 2. DMA results of vinylester resin after hydrothermal aging for 500 hours at $95^{\circ} \mathrm{C}$.

the evaporation of absorbed water. In fact, the maximum point of $\tan \delta$, which corresponds to the glass transition temperature $T_{\mathrm{g}}$ did not increase significantly after hydrothermal aging. It is therefore suggested that the changes in vinylester resin, i.e., the rupture strain $\varepsilon$ and elastic modulus $E$, with increasing hydrothermal aging time would have a relatively small effect on woven GFRP fracture ${ }^{(13)}$. The thermal stability of vinylester resin under long-term aging was also verified.

\subsection{Water absorption properties}

The weight gains $\Delta M$ and the swelling strains $\varepsilon_{\text {swell }}$ of the woven GFRP after immersion in water at various temperatures are shown in Fig. 3. The weight gain $\Delta M$ after immersion increased with immersion time and temperature until saturation was reached, especially for immersion at $40^{\circ} \mathrm{C}$ and $80^{\circ} \mathrm{C}$, which follows typical Fickian behavior. The immersion time required for saturation decreased rapidly with an increase in temperature: $400 \mathrm{~h}$ for $40{ }^{\circ} \mathrm{C}$, $100 \mathrm{~h}$ for $80^{\circ} \mathrm{C}$, and $25 \mathrm{~h}$ for $95^{\circ} \mathrm{C}$, respectively. These immersion times are similar to those for neat vinylester resin for the same temperatures ${ }^{(14)}$. Therefore, it is suggested that the diffusivity of the woven GFRP mainly depends on the diffusivity of the resin matrix along the thickness direction. However, in the case of immersion in water at $95{ }^{\circ} \mathrm{C}$, the GFRP weight gain continued to increase with immersion time. This can possibly be explained by the partial debonding at the fiber/matrix interface and micro-cracking in the resin matrix, which could result in the formation of gaps in which water retention occurs; this can be confirmed from the bleaching observed in Fig. $4^{(14),(15)}$. The swelling strain $\varepsilon_{\text {swell }}$ was negligible at all water temperatures. This could be explained by the inhibition of swelling of the resin matrix by the fiber reinforcement in the woven GFRP.

\subsection{Degradation of mechanical properties}

The degradation of woven GFRP after hydrothermal aging, in terms of the strength, 
(a) Weight gain $\Delta M$

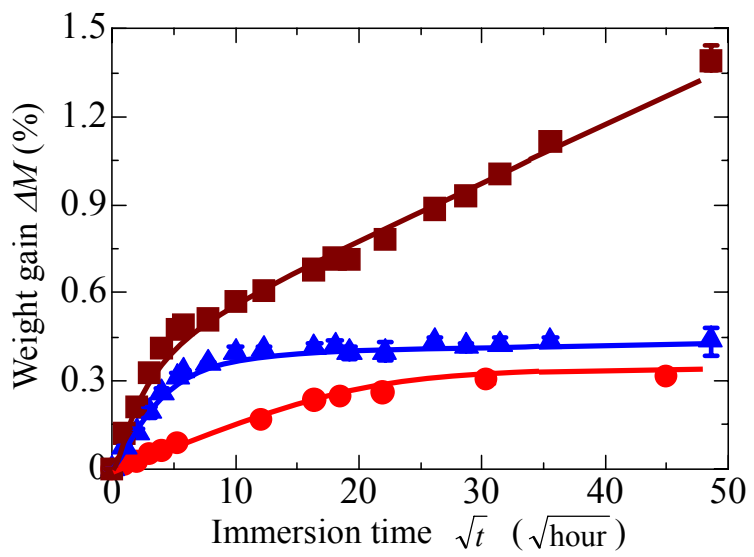

(b) Swelling strain $\varepsilon_{\text {swell }}$

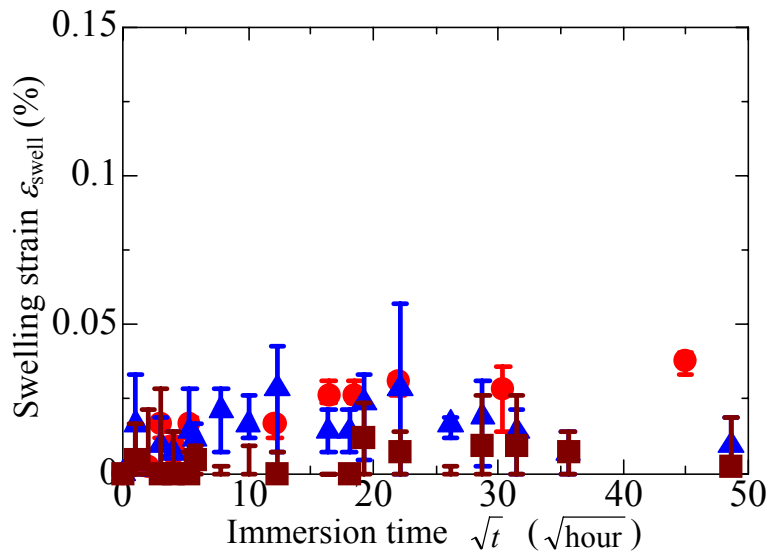

Fig. 3. Water absorption properties of woven GFRP laminates

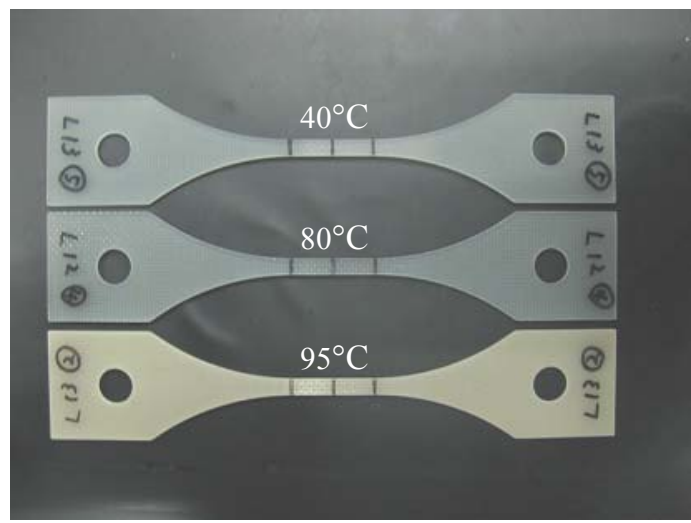

Fig. 4. Photograph of woven GFRP after immersion in water for 500 hour.

rupture strain, and stiffness, is shown in Fig. 5. The abscissa represents the square root of the immersion time, and the ordinate represents the properties of the woven GFRP. The stress-strain curves of the woven GFRP after hydrothermal aging for $1000 \mathrm{~h}$ at various water temperatures are shown in Fig. 6. From these results, it is obvious that the strength, rupture strain, and stiffness decreased with an increase in the hydrothermal aging as well as the temperature. The strength and the rupture strain reduced in the early stages of aging and have a tendency to saturate toward certain values with long-term aging. The strength and stiffness of the woven GFRP are strongly dependent on the volume fraction of the fiber reinforcement and on the area of its cross-section. The thickness of the GFRP plates varied from $1.95 \mathrm{~mm}$ to $2.49 \mathrm{~mm}$, and the total number of glass fiber bundles was controlled to be 20 plies. Thus, the stress and stiffness values distributed in a range of $25 \%$. In contrast, the rupture strain of the woven GFRP is determined by the fracture strain of the glass fiber; 
(a) Strength

Wet $\left(40^{\circ} \mathrm{C}\right)$

$\triangle$ Wet $\left(80^{\circ} \mathrm{C}\right)$

- Wet $\left(95^{\circ} \mathrm{C}\right)$

(b) Rupture strain

Wet $\left(40^{\circ} \mathrm{C}\right)$

$\Delta$ Wet $\left(80^{\circ} \mathrm{C}\right)$

- Wet $\left(95^{\circ} \mathrm{C}\right)$
Wet $\left(40^{\circ} \mathrm{C}\right)$

$\Delta$ Wet $\left(80^{\circ} \mathrm{C}\right)$

Wet $\left(95^{\circ} \mathrm{C}\right)$
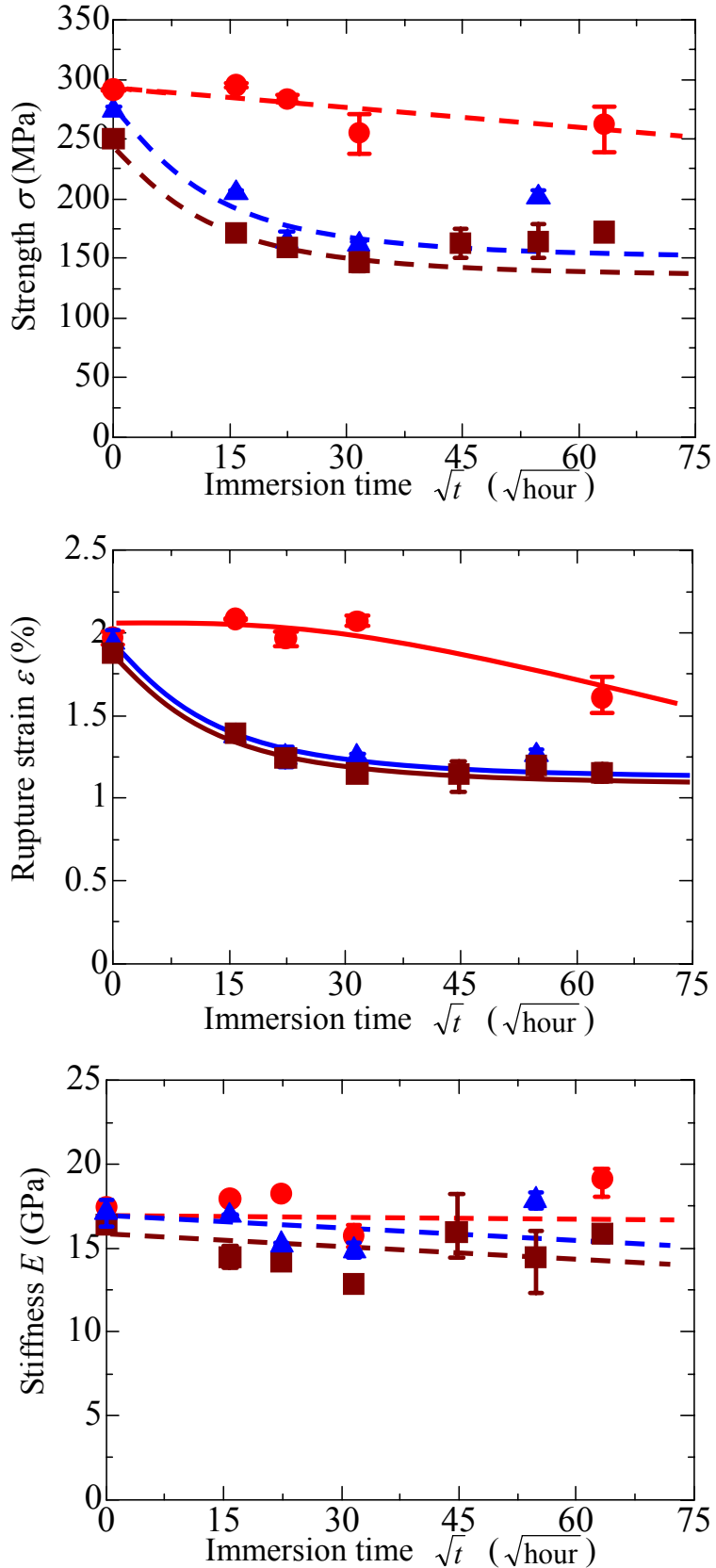

Fig. 5. Degradation of tensile properties after hydrothermal aging at various water temperatures.

therefore, the rupture strains shown in Fig. 5(b) were distributed over a relatively small range as compared to the other mechanical properties, which varied with the cross-sectional areas of the specimens. Hence, this study investigates the strength degradation of woven GFRP by examining their rupture strain.

The rupture strain of woven GFRP after long-term hydrothermal aging decreased to $65 \%$ and $60 \%$ of the initial values at $80{ }^{\circ} \mathrm{C}$ and $95{ }^{\circ} \mathrm{C}$, respectively. On the other hand, the rupture strain after aging at $40{ }^{\circ} \mathrm{C}$ decreased to $82 \%$ of its initial value after $4000 \mathrm{~h}$. This difference in degradation speed is thought to be caused by acceleration of the degradation of the constituents with increasing temperature. The strength (rupture strain) of the glass fiber decreases because of the growth of pre-existing surface flaws and reaches a steady-state strength value for each water temperature ${ }^{(16)}$. The value of this steady-state strength varies according to the applied stress (or strain) during hydrothermal aging. In this case, the 


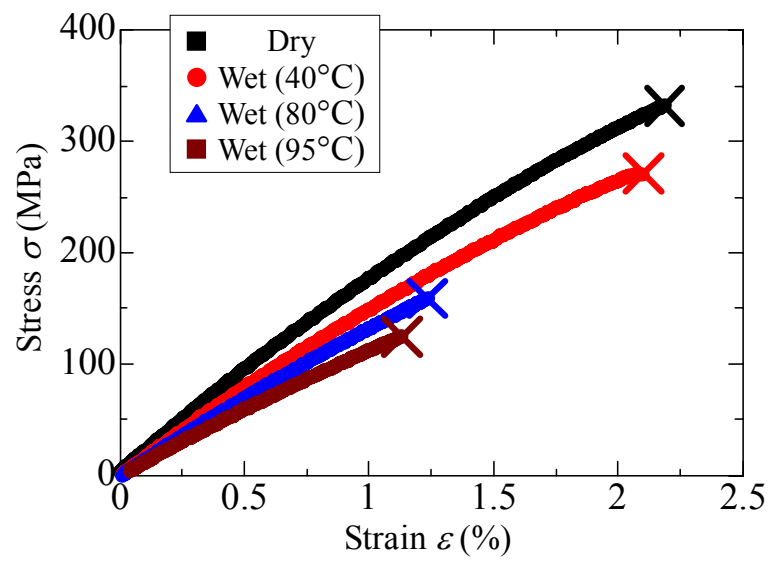

Fig. 6. Comparison of stress-strain curve of as-received and after hydrothermally aged specimens at various water temperatures for 1000 hours.

swelling strain is negligible, irrespective of the water temperature, and therefore, the strength degradation of the glass fiber is mainly caused by environmental agents. Moreover, the temperature appears to be sufficiently high to accelerate the degradation reaction and result in similar strength at $80{ }^{\circ} \mathrm{C}$ and $95{ }^{\circ} \mathrm{C}$. This accounts for the similar strength degradation behavior at $80{ }^{\circ} \mathrm{C}$ and $95^{\circ} \mathrm{C}$. The fiber/matrix interface adhesion also tends to degrade rapidly in the early stages of immersion in water and then saturates toward a certain strength ${ }^{(9),(17)}$. It is well known that vinylester resin has excellent corrosion resistance compared to conventional epoxy resins ${ }^{(13)}$. In fact, the stiffness and the strength of the vinylester resin reduce slightly after hydrothermal aging because of the plasticization due to water absorption. On the other hand, the rupture strain of vinylester increases after hydrothermal aging, which prevents resin fracture in woven GFRP after hydrothermal aging. It can be concluded that these irreversible and reversible changes in each constituent after hydrothermal aging, which is characterized by the saturation of certain parameters, induced the strength degradation behavior shown in Fig. 5.

\subsection{Strength degradation mechanisms}

SEM observations were conducted to investigate the failure mechanisms in woven GFRP and to clarify their strength degradation mechanisms after hydrothermal aging. Figures 7 and 8 show SEM images of the fracture surface of the woven GFRP after hydrothermal aging for $1000 \mathrm{~h}$ at various water temperatures.

The SEM images at low magnification (Fig. 7) of the fracture surface of an as-received specimen show fiber bundle fractures, which may be evidence of strong interfacial adhesion. On the other hand, it is obvious from the fracture surfaces that the resin matrix adhesion at the fiber surfaces decreases after hydrothermal aging with an increase in the water temperature. A fracture mode transition from fiber bundle fracture to fiber pull-out fracture was also observed. These results confirm the degradation at the fiber/matrix interfaces, and its acceleration with an increase in water temperature.

The SEM images at high magnification (Fig. 8) show that the glass fiber fracture surfaces flatten with an increase in the water temperature. The failure of the glass fibers is commonly caused by surface flaws, and these flaws grow with the applied stress and as a result of environmental factors. The growth of these flaws results in the strength degradation of glass fibers and flat fiber surfaces, which are characterized by three distinct regions: mirror, mist, and hackle regions ${ }^{(15)}$. Fiber strength degradation resulting from hydrothermal aging was ascertained from the flattening of the fiber fracture surfaces with an increase in the water temperature. This can be confirmed from the degradation in the strength and the rupture strain of woven GFRP shown in Fig. 6.

Figure 9 shows the fracture surface of the woven GFRP after long-term hydrothermal 


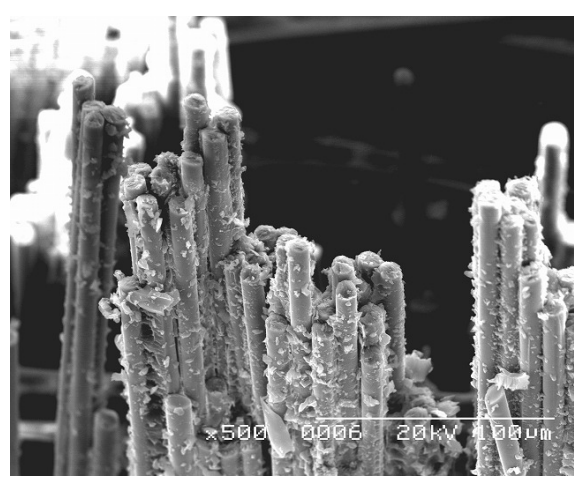

(a) As-recieved (dry)

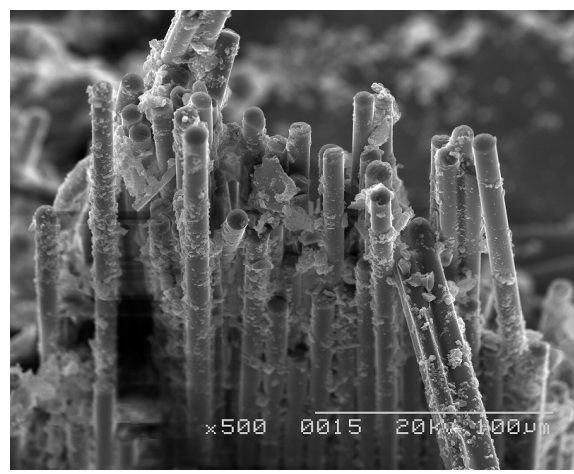

(c) $80^{\circ} \mathrm{C} \quad 1000$ hours (wet)

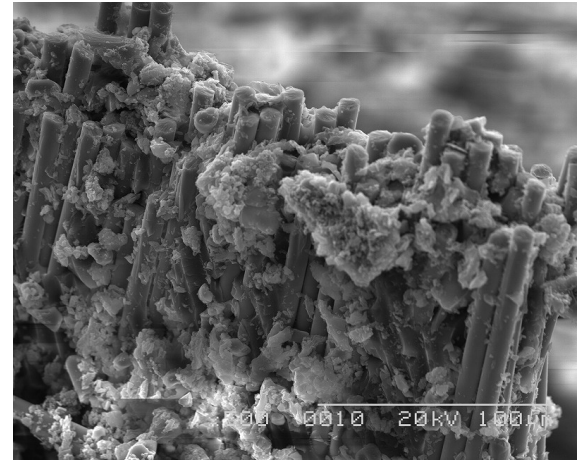

(b) $40^{\circ} \mathrm{C} \quad 1000$ hours (wet)

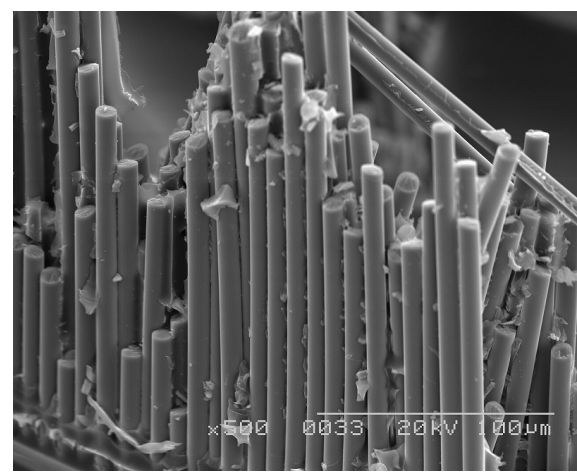

(d) $95^{\circ} \mathrm{C} \quad 1000$ hours (wet)

Fig. 7. Comparison in fracture surface of woven GFRP before and after hydrothermal aging for 1000 hours at various water temperatures (low-magnification SEM images).

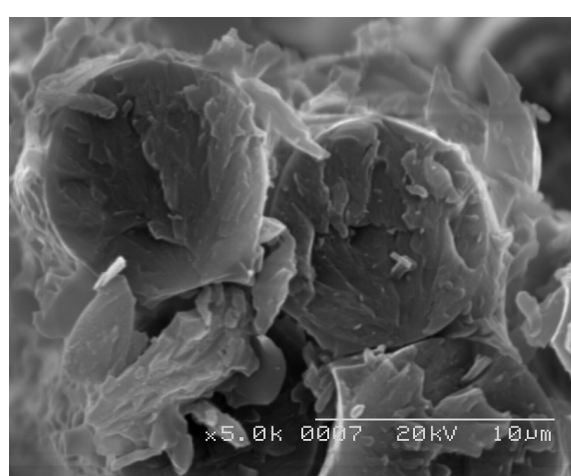

(a) As-recieved (dry)

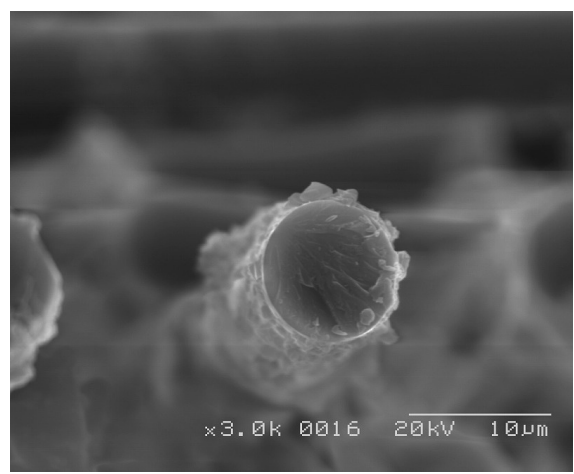

(c) $80^{\circ} \mathrm{C} \quad 1000$ hours (wet)

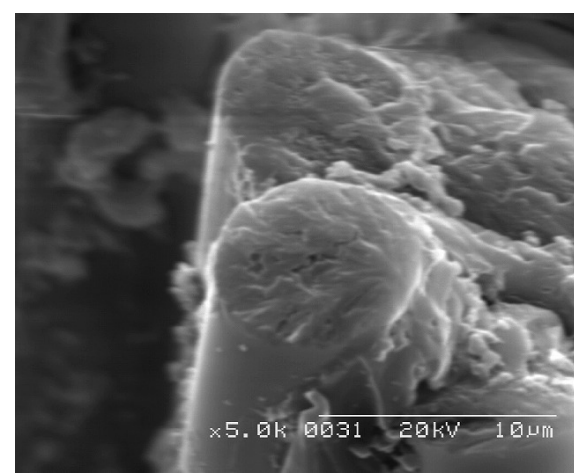

(b) $40^{\circ} \mathrm{C} \quad 1000$ hours (wet)

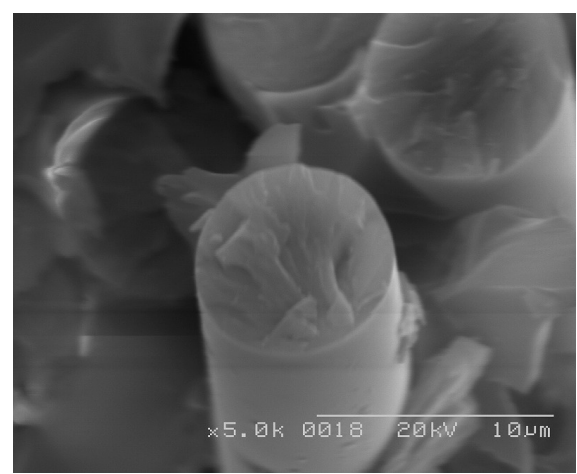

(d) $95^{\circ} \mathrm{C} \quad 1000$ hours (wet)

Fig. 8. Comparison in fracture surface of woven GFRP before and after hydrothermal aging for 1000 hours at various water temperatures (high-magnification SEM images). 


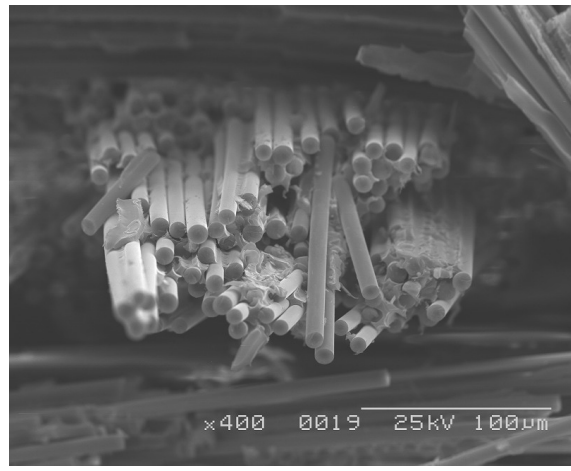

(a) $95^{\circ} \mathrm{C} 2000$ hours

(low magnification)

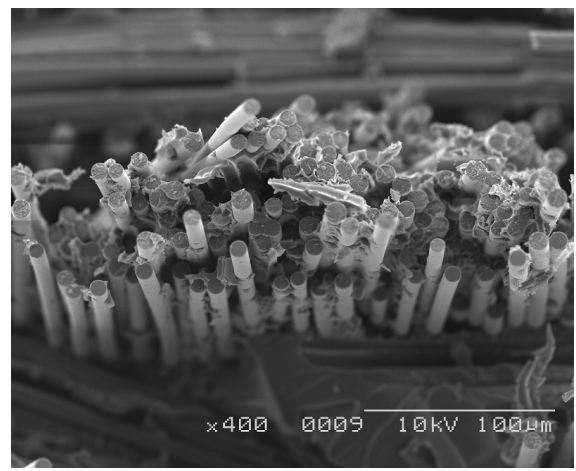

(c) $95^{\circ} \mathrm{C} \quad 3000$ hours

(low magnification)

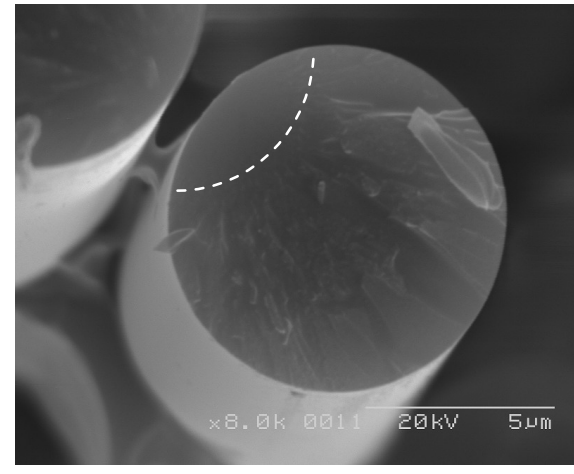

(b) $95^{\circ} \mathrm{C} \quad 2000$ hours

(high magnification)

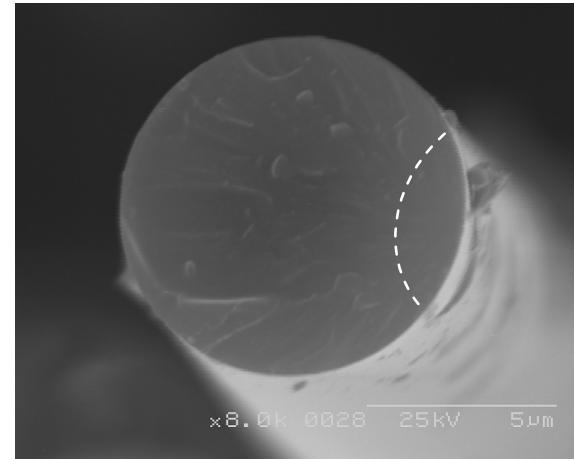

(d) $95^{\circ} \mathrm{C} \quad 3000$ hours

(high magnification)

Fig. 9. Comparison of fracture surface of woven GFRP after long-term hydrothermal aging at $95^{\circ} \mathrm{C}$.

aging at $95{ }^{\circ} \mathrm{C}$. The boundaries of the mirror zone and the hackle zone are indicated by dotted lines. It is described in Fig. 9 that the mirror zone area does not change after long-term hydrothermal aging, which is consistent with the decrease and the saturation behavior of the woven GFRP strength shown in Fig. 6. It is suggested in this figure that the fracture mode transition to be completed: the transition to fiber pull-out and to fiber fracture surface flattening. From these results, it is concluded that the strength of woven GFRP after long-term hydrothermal aging strongly depends on the strength of the glass fiber and the fiber/matrix interface.

As described previously, the results of the study on the fracture surfaces of the woven GFRP lead to several important conclusions:

1. The fracture surface of glass fibers flattens and the area of mirror zone increases with a decrease in the fiber strength; these processes are initiated by the growth of the surface flaws.

2. The transition from fiber bundle fracture to fiber pull-out fracture and the formation of a smooth fiber surface confirms the degradation of fiber/matrix interfacial adhesion.

3. The transition in the fracture mode and the slight degradation of the vinylester resin suggest that the strength degradation of woven GFRP after long-term hydrothermal aging strongly depends on the strength of the glass fiber and the fiber/matrix interface.

\section{Conclusions}

Based on the findings in this study, the following conclusions were obtained:

- The weight gain of the woven GFRP exhibited Fickian behavior at $40{ }^{\circ} \mathrm{C}$ and $80{ }^{\circ} \mathrm{C}$ : a 
rapid initial weight gain, which slows down and saturates to a certain maximum value after long-term immersion in water. The weight gain kept increasing for woven GFRP immersed in water at $95{ }^{\circ} \mathrm{C}$, which is possibly due to the damage to the fiber/matrix interface, observed as the bleaching of the GFRP. The swelling strain is negligible at all water temperatures.

- The strength and the rupture strain of woven GFRP decreases with hydrothermal aging and the rate of decrease accelerates with an increase in water temperature. In addition, both the strength and the rupture strain decrease in the early stages of aging and tend to saturate with long-term aging, especially at high water temperatures.

- SEM images of the fracture surfaces show a transition of the fracture mode from fiber bundle fracture (strong fiber/matrix interface adhesion) to fiber pull-out fracture (weak fiber/matrix interface adhesion). In addition, the fracture surface of the glass fibers flattens, with the decrease in fiber strength. These SEM observations suggest that the strength degradation of woven GFRP is strongly influenced by the degradation of the fiber reinforcement and the fiber/matrix interface.

\section{Acknowledgement}

This work was supported in part of Reports of Grants-in-Aid for Scientific Research (C) No. 20560089.

\section{References}

(1) Y. Fujii, "Importance of Damage Analysis", Journal of the Society of Materials Science 54, No. 1(2005), pp.112-113.

(2) J. N. Price and D. Hull, "Effect of Matrix Toughness on Crack Propagation during Stress Corrosion of Glass Reinforced Composites", Composites Science and Technology 28 (1987), pp. 193-210.

(3) P. J. Hogg, S. N. Sapalidis and S. J. Youd, "High temperature acidic stress corrosion of glass fibre composites: Part I Effect of fibre type", Journal of Material Science 32, No. 2 (1997), pp. 309-316.

(4) H. Kawada and V. K. Srivastava, "The effect of an acidic stress environment on the stress-intensity factor for GRP laminates", Composites Science and Technology 61, No. 8(2001), pp.1109-1114.

(5) C. L. Schutte, W. McDonough, M. Shioya, M. Mcauliffe and M. Greenwood, "The Use of a Single-Fiber Fragmentation Test to Study Environmental Durability of Interfaces/Interphases between TGEBA/mPDA Epoxy and a Glass Fiber: the effect of moisture", Composites 25, No. 7 (1994), pp.617-624.

(6) C. J. Jones, R. F. Dickson, T. Adam, H. Reiter and B. Harris, "Environmental fatigue of reinforced plastics", Composites 14, No. 3 (1983), pp. 288-293.

(7) F. R. Jones, J. W. Rock and A. R. "Wheatley, Stress corrosion cracking and its implications for the long-term durability of E-glass fibre composites", Composites 14, No. 3(1983), pp. 262-269.

(8) C. S. Helbling and V. M. Karbhari, "Investigation of the sorption and tensile response of pultruded E-glass/vinylester composites subjected to hygrothermal exposure and sustained strain", Journal of Reinforced Plastics and Composites 27 (2008), pp. 613-638.

(9) M. Kotani, Y. Shibata and H. Kawada, "Evaluation of GFRP Strength under Water Environment Considering Interfacial Strength Degradation", Proceeding of 17th International Conference on Composite Materials (JUL 2009), in CD-ROM.

(10) K. Liao and E. Y. M. Tan, "In situ tensile strength degradation of glass fiber in polymer composite", Scripta materials 44, No. 5 (2001), pp.785-789. 
(11) JIS K 7112, Plastics - Methods of determining the density and relative density of non-cellular plastics.

(12) A. Kobiki, S. Itoh, and H. Kawada, "Quantification of fiber strength degradation in SFC under water environment", Transactions of the Japan Society of Mechanical Engineers Series A 73, No. 732 (2007), pp. 82-89 (in Japanese).

(13) L. Ghorbel and D. Vanlentin, "Hydrothermal Effects on the Physico-Chemical Properties of Pure and Glass Fiber Reinforced Polyester and Vinylester Resins" Polymer Composites 14, No. 4 (1993) , pp. 324-334.

(14) M. Kotani, K. Nakamichi, Y. Yasufuku, and H. Kawada, "Damage Evolution of Delayed Fracture in Woven GFRP under Hot Water Environment", Advanced Materials Research 79-82 (2009), pp. 1923-1926.

(15) L. Gautier, B. Mortaigne, V. Bellenger, "Interface damage study of hydrothermally aged glass-fibre-reinforced polyester composites", Composite Science and Technology 59, No. 16 (1999), pp. 2329-2337.

(16) S. Feih, K. Manatpon, Z. Mathys, A. G. Gibson and A. P. Mouritz, "Strength degradation of glass fibers at high temperatures", Journal of Materials Science 44 (2009), pp.392-400.

(17) M. Kotani, Y. Shibata, Y. Yamamoto and H. Kawada, "Evaluation of Interface Properties in GFRP under Water Environment using Different Fracture Mode Test", 11th Japan International SAMPE Symposium \& Exhibition (2009), in USB memory. 